\title{
The Construction and Use of a Windowless Optical Cell for the Flow Injection Analysis of Chloride Ion
}

\author{
Jae-Ho Lee," Mee-Ae Han, Seong-Woo Kang, Seong-Seok Seo, and Hoon Hwang \\ Department of Chemistr: Kangwon Natonal University, ChunChon 192-1, Korea. "E-mail: hoonatakangwonac.kr \\ ${ }^{\top}$ Kangwon Science High School, Wonloo 220-121, Korea \\ Received September 9, 2004
}

Key Words : Windowless optical cell, Reflectance spectrometry, Precipitate, Chloride

Determination of chloride ion in aqueous samples by the Mohr titration has been well known and introduced in most analytical chemistry textbooks. ${ }^{1.2}$ Jlowever, as in most titration analyses, the Molr method requires the use of an indicator (chromate, $\mathrm{CrO}_{4}{ }^{2}$ ) ol proper concentration. It also requires the adjustment of $\mathrm{pH}$ of the chloride containing sample solution to accurately determine the end point. One way to avoid such troublesome requirements and at the same time to enhance the efficiency of the chloride analysis is the use of a flow injection analysis (FIA) technique equipped with an optical flow through cell. As a stream of solution containing $\mathrm{Cl}$ ion is mixed with another stream of $\mathrm{Ag}$ ion, the precipitation reaction between the two ions takes place. An optical property of the resulting solution is measured as the solution containing fine $\mathrm{AgCl}$ particles passes through a flow through cell. The relative change in magnitude of the optical properties of various sample solutions may therefore be quantitatively related to concentrations of $\mathrm{Cl}$ ion in sample solutions. However, the conventional optical flow through cell used in various flow injection analyses possesses an inherent problem of particle deposit on its window surface when solutions containing precipitation reaction products such as fine silver chloride particles flow through it.

Hanghui I iu and Purnendu K. Dasgupta introduced a new concept of an optical cell. Since the optical cell designed and used in their works didn't have any windows but utilized the dynamic growing and falling of droplets of a solution as an optical cell, the cell was named a 'windowless optical cell'. They used such a cell as a reproducible collector of a gas sample and as a windowless optical cell for absorbance detection. They also suggested that the windowless optical cell could be used for both turbidimetric and nephelometric detections." However, since the use of windowless optical cell was based on either transmittance or scattering of the incident light, their applications were limited to analyses of optically transparent solutions. Since the solution containing fine $\mathrm{AgCl}$ particles becomes optically opacue as the concentration of $\mathrm{Cl}^{-}$ion increases, the measurement of either transmitted or scattered light from the solution containing $\mathrm{AgCl}$ particles could not be quantitatively related to the concentration of $\mathrm{Cl}^{-}$ion in the sample solution.

In this paper the design and use of the windowless optical cell was properly modified for the reflectance spectrometry ${ }^{5-8}$ so that the intensity of reflected light from the solution containing fine $\mathrm{AgCl}$ particles could be measured and quantitatively related to the chloride concentration in the sample solution.

FIA System. Figure 1 shows a schematic diagram of the FlA system used in this work. The first channel (A) of the peristaltic pump (C. Ismatec $\mathrm{MV}$ ) carries $0.10 \mathrm{M} \mathrm{AgNO}_{3}$ solution and the second channel (B) catries deionized water



Figure 1. Schematic Diagram of the li] $\Lambda$ syskem. $A$ : channel for $0.10 \mathrm{M} \mathrm{AgNO}$, solution. B: channel for deionized water. C: peristaltic pump. [D: sample injection valve. F: mixing T. F: delay: line. G: the optical detection system

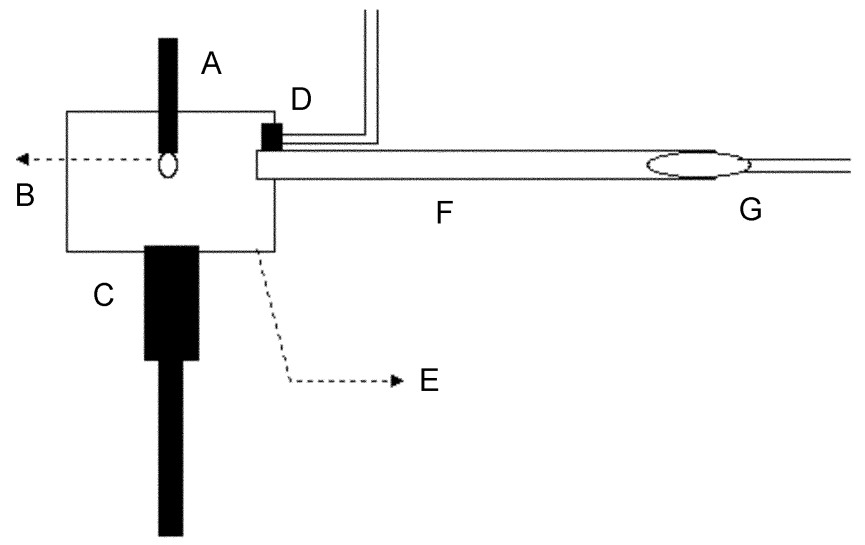

Figure 2. Cross Sectional View of the Optical I)tection System based On the Rellectance Spectrometry. A: 'Iedlon tubing for inlet, B: droplet of solution. C: black PVC tuhing for drain. D: the blue sensitive photodiode $w$ ith its teminals connected to the recorder. I: black PVC tubing for housing the optical components. lit glass tubing to guide the light trom the light emitting diode (LLD), G: high luminescence blue LED with its terminals connected to a $D C$ power supply. 
through a sample injection valve (D, Rheodyne 6-port sample injection valve). When a sample solution containing $\mathrm{Cl}^{-}$ion is injected into the flow stream of the first channel, the precipitation reaction between chloride and silver ions begins to take place as the two solutions meet at mixing I (E) and comes to completion while passing the delay line (F). Then, the solution containing fine white particles of $\mathrm{AgCl}$ precipitate flows into the optical detection system (G).

Optical Detection System. Figure 2 shows the cross sectional view of the optical detection system housed in a black PVC compartment ( $\mathrm{G}$ i.d.: $7 \mathrm{~mm}$. length: $2 \mathrm{~cm}$ ). When a solution is introduced into the optical detection system through a tube (A, PIFE tubing of $1 \mathrm{~mm}$ i.d. and 5 $\mathrm{cm}$ in length), the formation and falling of droplets (C) of the solution occurs continuously at the bottom tip of the tube. The light from the radiation source ( $\mathrm{E}$, high luminescence blue light emitting diode) guided through a glass tubing (D. i.d.: $4.5 \mathrm{~mm}$ ) is shed over the surface of each droplet throughout its lifetime and the intensities of reflected light are measured at the radiation detector $(B$, a blue sensitive photodiode) placed on the same side with the radiation source. Two black PVC tubes ( $\mathrm{F}$ and $\mathrm{H}$ ) are connected at the bottom of the compartment for drain.

Shape of the Signal. Even when a solution introduced into the optical detection system does not contain any precipitate particles, the outputs of the photodiode are recorded as signals fluctuating in magnitude. Such phenomenon could be regarded inevitable due to the periodic formation and falling of droplets, which act as a windowless optical cell and therefore be accepted as a characteristic behavior of the optical detection system employed in this work. As the stream of a solution carrying fine white particles of the $\mathrm{AgCl}$ precipitate passed through the inlet tube of the optical detection system, due to the same dynamic formation/falling of droplets, the resulting signal also fluctuated. However, the signal showed a gradual increase in its magnitude and subsequent decrease down to the baseline level. Even with such fluctuations in the signal magnitude, as we could see in figure 3 , the signals obtained with a given chloride standard were found to be highly



Figure 3. The signals obtained with three repetitive injections lor each chloride standard. The concentrations of the chloride standards used were, from left to right. $2.0 \times 10^{+} \mathrm{M} .4 .0 \times 10^{+} \mathrm{M}$, $6.0 \times 10^{-4}$ M. $8.0 \times 10^{-4}$ M. $2.0 \times 10^{-3}$ M. and $4.0 \times 10^{-3} \mathrm{M}$.



Figure 4. The calibration curve for the determination of $\mathrm{Cl}$ ion in the concentration range of $20 \times 10^{-4} \mathrm{M}$ to $6.0 \times 10^{-2} \mathrm{M}$.

reproducible.

Calibration Curve. The chloride standards of various concentrations ranging from $1.0 \times 10^{-1} \mathrm{M}$ to $1.0 \times 10^{-1} \mathrm{M}$ were prepared and used to construct the calibration curve. In this work two different lengths (volumes) of the sample loop were used, a sample loop of $112 \mu \mathrm{l}$, for the chloride standards of $2.0 \times 10^{-4}-4.0 \times 10^{-3} \mathrm{M}$ and another sample loop of $28 \mu \mathrm{l}$. for the chloride standards of $8.0 \times 10^{-3} \mathrm{M}$ and higher. The sinaller sample loop was necessary to avoid the clogging of tubing by the highly concentrated fine particles of $\mathrm{AgCl}$ precipitate. The optimum flow rate of the system to obtain the lowest detection limit was $0.995 \mathrm{~mL} / \mathrm{min}$. Figure 4 shows a linear relationship between the relative magnitudes of signals and the chloride concentrations from $2.0 \times$ $10^{-4} \mathrm{M}$ to $6.0 \times 10^{-2} \mathrm{M}$ with the standard deviations of less than the size of the symbols used. The detection limit was found to be $2.0 \times 10^{-4} \mathrm{M}$ and the repetitive injections of 20 / hr were possible under the current optimum conditions.

\section{References}

1. Day: R. A.: Underwood. A. L. Otamitative Andysis. 6th ed.: Prentice Ilall: New Iersey. U.S.A.. 1991: p 231.

2. Harris. D. C. Quantitative (hemicat inafisis. 4h ed. W. H. Freeman and Company: New York. UIS.A. 1995: p 173.

3. Liu. H.: Dasgupta. P. K. Anal Chem. 1995. 67. 4221.

4. Liu. H.: Dassupta. P. K. Anal. Chim. Acta 1996. 326. 13.

5. Hwang. H.: Jung. D. J. Korem Chem. Soc 2000. ff(4). 316.

6. Jwang. 11.: 1.ee. K. J. Korean (hent Soc 2001, f5(1), 45.

7. I wange. 1. I. Korean ('hem. Soc. 2001. t5(6). 513.

8. 1 Jwang. I. I. Koreat ('hem. Soc. 2001. $+6(5), 471$. 